\title{
Fatores de risco e de proteção associados à alteração de fala e linguagem em uma amostra nacionalmente representativa de crianças de 4 a 5 anos de idade
}

\author{
Comentado por: Daniela Regina Molini-Avejonas ${ }^{1}$
}

Harrison LJ, McLeod S. Risk and protective factors associated with speech and language impairment in a nationally representative sample of 4- to 5-yearold children. J Speech Lang Hear Res. 2010;53(2):508-29.

As autoras iniciam o artigo mencionando a proporção significativa de crianças com alteração de linguagem e fala no período pré-escolar e apontam a necessidade da identificação destas crianças, assim como o tratamento das mesmas, neste período que é crucial para o desenvolvimento infantil, podendo reduzir a severidade e a longevidade das alterações de fala e linguagem.

Para tanto, os profissionais da atenção primária devem ser capazes de identificar as crianças que podem ser grupo de risco para alteração de fala e linguagem. Entretanto, os métodos utilizados por esses profissionais para diagnosticar a alteração tendem a ser: comparação com crianças da mesma idade, queixas dos pais, e checklist dos principais marcos do desenvolvimento de linguagem. A proposta das autoras é que outro método também seja utilizado: o reconhecimento e identificação dos fatores de risco e de proteção para o desenvolvimento de fala e linguagem.

Ainda não foi desenvolvida, testada ou validada uma lista de fatores de risco para ser utilizada pelos profissionais da atenção primária. Esta dificuldade surge pela necessidade de se levar em consideração a complexa inter-relação existente entre os fatores biológicos, sociais, psicológicos e individuais de cada criança no desenvolvimento de linguagem, ou seja, a lista deve contemplar uma ampla gama de variáveis, como histórico familiar, status sócio-econômico, informações perinatais, condições de saúde, ordem de nascimento, gemelaridade, nível educacional dos pais, número de irmãos, sexo, temperamento, hábitos orais, língua materna, saúde mental dos pais, idade materna ao nascimento, vulnerabilidade do bairro, tempo que os pais gastam com seus filhos e outros.

As autoras revisaram 16 estudos e a maioria deles analisou apenas um ou dois dos fatores citados acima. Os fatores de risco mais consistentemente citados nestes estudos foram: história familiar de alteração de fala e/ou linguagem, sexo masculino e intercorrências perinatais. Os demais fatores apresentam achados muito contraditórios, provavelmente pela diferença dos estudos quanto ao tamanho e natureza da amostra, métodos utilizados para avaliar a alteração de fala e linguagem, e número de fatores de risco analisados.

O presente estudo coletou dados sobre a linguagem de 4.983 crianças australianas, entre quatro e cinco anos de idade, de quatro diferentes maneiras: queixas dos pais sobre a linguagem expressiva das crianças, queixas dos pais sobre a linguagem receptiva das crianças, uso de serviço fonoaudiológico nos últimos 12 meses e escores obtidos em compreensão de vocabulário do Adapted Peabody Picture Vocabulary Test -III. Cada um deles identificou um grupo de crianças com alteração e outro grupo sem alteração.

Trinta e um fatores de risco para o desenvolvimento de linguagem foram relacionados com os dois grupos resultantes (com alteração e sem alteração) de cada um dos quatro métodos de detecção de alteração de linguagem. Foi utilizada estatística descritiva, análise de regressão logística bivariada e multivariada. $\mathrm{Na}$ análise bivariada foram confirmados 29 fatores. Contudo, quando testados na análise multivariada, apenas 19 apresentaram significância e nove foram mais consistentes, sendo os de risco: sexo masculino, problemas de audição, e temperamento reativo; e os de proteção do desenvolvimento de linguagem: temperamento persistente e sociável e boa saúde mental materna. Ter um irmão mais velho, ter pais que não possuem o inglês como língua materna e ter pais que passam tempo com seus filhos em atividades educativas, foram fatores que apresentaram significância estatística, mas dependendo do método utilizado para detecção da alteração de linguagem, foram considerados de risco ou de proteção.

Os achados deste estudo confirmam que a alteração de fala e linguagem na infância é influenciada por múltiplos fatores e os mesmos são discutidos um a um pelas autoras, que concluem que os fatores de risco e de proteção, juntamente com observações da fala da criança e dos marcos do desenvolvimento de linguagem infantil, podem ser um guia útil para os profissionais da atenção primária que visam identificar precocemente crianças que se beneficiariam de terapia fonoaudiológica.

(1) Departamento de Fisioterapia, Fonoaudiologia e Terapia Ocupacional da Faculdade de Medicina da Universidade de São Paulo

Endereço para correspondência: Daniela Regina Molini-Avejonas. R. Cipotânea, 51, Cidade Universitária, São Paulo (SP), Brasil, CEP: 05360-000.

E-mail: danielamolini@usp.br 